MARICELA GONZÁLEZ CRUZ MANJARREZ INSTITUTO DE INVESTIGACIONES ESTÉTICAS, UNAM

\title{
Tina Modotti y el muralismo, un lenguaje común
}

$\mathrm{T}$

INA MODOTTI ES AHORA una figura popular, sus fotografías se cotizan a precios insospechados y se ha convertido en referente cultural en determinados sectores sociales. M ucho antes de este interés, historiadores como Xavier M oyssén se ocuparon de ella. En el artículo "Una colección de fotografías de Tina M odotti y José M aría Lupercio", de I975, trató sobre la colección de fotos de Tina M odotti del iie. ${ }^{\mathrm{I}}$ Ahora, recordando con agradecimiento los consejos y la solidaridad académica, además del trato amable que siempre tuvo como ser humano el maestro Xavier M oyssén, dedico este artículo a su memoria, precisamente en los Anales del Instituto, porque alrededor de is años estuvo a cargo de su dirección.

D esde la fecha del artículo de M oyssén hasta ahora, con Tina ha sucedido precisamente lo que su compañero Vittorio Vidali tanto temía: se ha transformado en un estereotipo y en un objeto de consumo. Su figura es hoy cada vez más reconocida, aunque menos conocida. Es, como Frida Kahlo o el Che Guevara, un símbolo ambiguo, o se le valora desde una perspectiva feminis-

I. Cfr. Anales del Instituto de Investigaciones Estéticas, núm. 44, 1975. Esta colección consta de is fotografías impresas por T ina M odotti, que reproducen obra de caballete de Rivera, así como sus murales de la Secretaría de Educación Pública y Chapingo, y sólo 5 de murales de $O$ rozco en San Ildefonso, entre las que está un retrato del propio O rozco pintando. Las tomas fotográficas las realizó T ina M odotti entre 1927 y 1930 . Para mayor información, cfr. M aricela González, Tina M odotti y el muralismo mexicano, M éxico, unAM-Instituto de Investigaciones Estéticas, 1999 (Colecciones del Archivo Fotográfico, I). 
ta, asociándola con mujeres como Nahui Ollin, Antonieta Rivas M ercado, Lupe $\mathrm{M}$ arín, Concha $\mathrm{M}$ ichel o M aría Izquierdo, con lo cual se destaca su personalidad y su vida, pero se minimiza incluso su propia obra.

Para que las diferentes facetas de esta fotógrafa cobren sentido, tendríamos que considerar su trayectoria de manera integral, articulando, por ejemplo, su vínculo sentimental y artístico con el famoso fotógrafo norteamericano Edward Weston, su actitud independiente frente a determinaciones sociales y morales rígidas, su trabajo fotográfico de gran calidad y significación para la fotografía de vanguardia en M éxico en la década de los treinta, su proximidad con el movimiento muralista mexicano, así como su firme convicción comunista y su trabajo solidario en la Guerra Civil Española. ${ }^{2}$

El proceso de cambio en el trabajo fotográfico de Tina coincide con su asimilación de la cultura en M éxico. El estilo desarrollado por Edward Weston de trabajar una fotografía directa, formalmente expresiva, libre de detaIles 0 anécdotas, en un principio influyó en Tina M odotti, pero, en la medida que se definía su postura política, su propio trabajo se transformó: sin descuidar el aspecto formal de la imagen, la asocia a una foto de planteamiento social, se vincula con los muralistas, reproduce sus obras y trabaja en El M achete, publicación creada por el Sindicato de 0 breros, T écnicos, Pintores y Escultores en i924. ${ }^{3}$ Un claro ejemplo de la nueva orientación de su trabajo fue la exposición realizada en la Biblioteca N acional en $\mathrm{I}^{2} 29^{4}$ (figura I).

Tina M odotti estableció una relación diversa con los muralistas,5 colaboró con fotos para la difusión de los murales, como en el caso de las obras de José Clemente O rozco, Diego Rivera y M áximo Pacheco; se vinculó con pinto-

2. Considero que uno de los estudios más completos que comprenden estos aspectos de Tina M odotti es el de M argaret Hooks, Tina M odotti, Photographer and Revolutionary, Londres, $H$ arper Collins-Pandora, I993, en el cual, además, la autora incluye una excelente investigación iconográfica. Existe una traducción al español de la obra: Barcelona, Plaza \& Janés, 1998.

3. Esta publicación incluía grabados y fotografías, y era de un formato grande que podía ser pegado en las paredes. En 1929 El M achete fue cedido al Partido Comunista M exicano y cambió sus características; resultó menos atractivo visualmente y también se modificó su formato.

4. La exposición fue organizada por Baltasar D romundo, con la participación de Concha $M$ ichel interpretando canciones revolucionarias durante la inauguración, con palabras de D romundo y Siqueiros en la clausura. Esta exposición fue recreada en el Centro de la Imagen, a partir de la investigación de Elisa Lozano y Jesús Sotelo. Véase el catálogo Tina M odotti, nueva mirada 1929 , M éxico, cnca, 2000.

5. El primer estudio serio que trata de la relación de Tina M odotti con los muralistas es la tesis sustentada en 1995 por M ariana Figarella para obtener la maestría en historia del arte en 


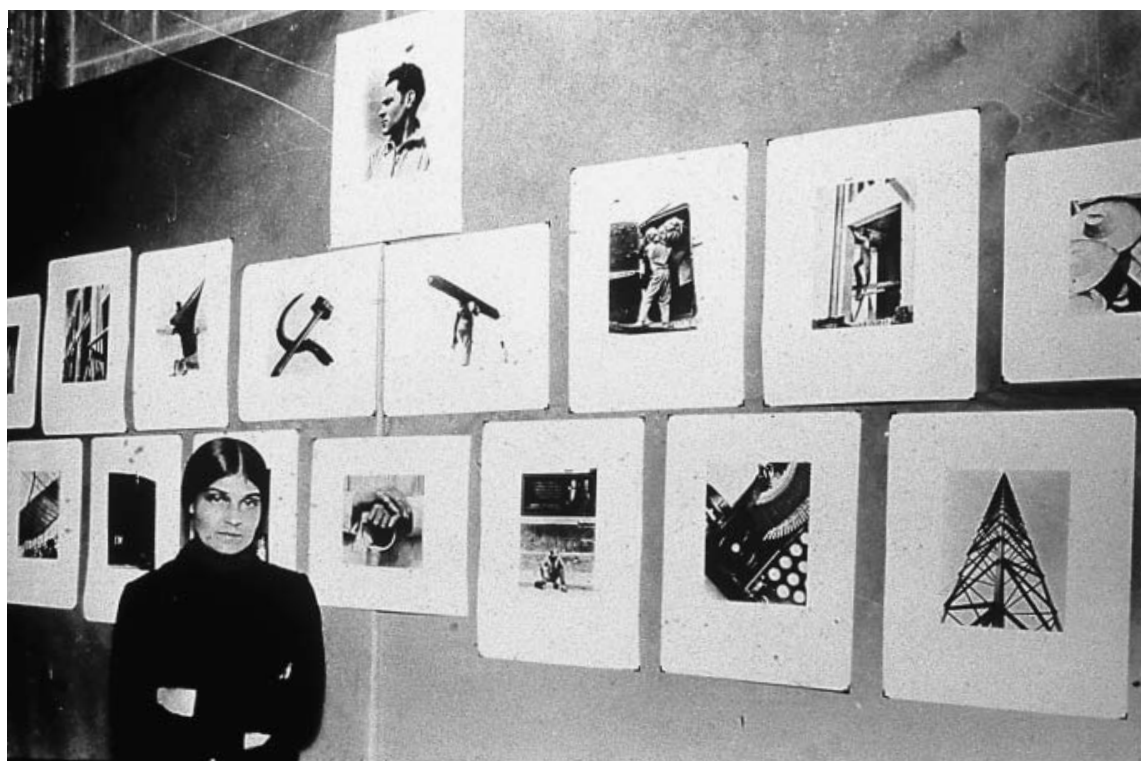

Figura I. Tina Modotti en su exposición de la Biblioteca N acional de la U niversidad, I929. Foto tomada de: M argaret Hooks, Tina M odotti, Photographer and Revolutionary, Londres, Pandora, 1993, p. 193.

res como Diego Rivera, D avid Alfaro Siqueiros y M iguel Covarrubias e, incluso, estableció una relación íntima con otros, como Xavier Guerrero (figura 2).

Su cercanía con los muralistas no sólo fue laboral o afectiva, pues existió una proximidad con ellos en cuanto a su actitud frente a la vida y la percepción de la realidad mexicana de los años veinte. Además, hubo una propuesta artística y cultural común en la cual confluían las revoluciones mexicana y soviética, la vanguardia y el nacionalismo. Encontramos paralel ismos formales y conceptuales entre su fotografía y el muralismo, tales como la representación de la naturaleza y del campo, donde se destaca la presencia de nopales, maíz y magueyes; también aluden a instrumentos de trabajo y a elementos distintivos de sectores populares; así, aparecen machetes, palas, cananas y sombreros de campesinos; finalmente, registran escenas populares, fiestas tradicionales, corridos, artesanías y costumbres.

la Facultad de Filosofía y Letras de la unam, titulada Edward W eston y Tina M odotti en M éxico. Su inserción dentro de las estrategias estéticas del arte posrevolucionario, en prensa. 




Figura 2. Clemente O rozco pintando un detalle de La familia campesina, Escuela $\mathrm{N}$ acional Preparatoria, San Ildefonso. Colección Tina M odotti, Archivo Fotográfico iie-unam.

Expresan también un discurso similar al exaltar el socialismo, al mostrar la oposición de clases sociales, en la constante alusión al trabajo y en el enaltecimiento de los trabajadores, ya sean obreros, artesanos o campesinos. 0 tros temas comunes son la productividad o la referencia a los líderes sociales. D e esta manera, los temas se repiten con múltiples variantes y encontramos representaciones de obreros, campesinos, niños, mítines políticos, manifestaciones populares, manos de trabajadores, gente del pueblo; elementos simbólicos como mazorcas, la hoz, cananas, guitarras, banderas y estrellas (figura 3 ).

Estos paralelismos entre Tina y los muralistas están inscritos en una red en cuyo entramado convergen distintos planteamientos y propuestas, desde diferentes lenguajes artísticos que integran el imaginario mexicano, al cual inevitablemente nos remitimos al tratar de la cultura y el nacionalismo de los años veinte a los cincuenta. D e esta manera coinciden, a veces contraponiéndose, imágenes cinematográficas como las de Eisenstein y Emilio Indio Fernández, con la fotografía de G abriel Figueroa, o incluso hasta el cine de Luis 




Figura 3. Diego Rivera, Símbolos del nuevo orden, Salón de Actos, U niversidad Autónoma Chapingo. Colección Tina M odotti, Archivo Fotográfico iie-un am.

Buñuel. La pintura de Carlos M érida, M anuel Rodríguez Lozano, Roberto M ontenegro, Rufino Tamayo y los muralistas de varias generaciones. El grabado de Leopoldo M éndez y los miembros del Taller de Gráfica Popular. La fotografía de M anuel Álvarez Bravo, Agustín Jiménez y Luis M árquez.

Un ejemplo significativo de esta mirada común con el muralismo lo encontramos en las tomas fotográficas que Tina realizó al reproducir los murales de Rivera en la Secretaría de Educación Pública y en Chapingo, así como los murales de 0 rozco en San Ildefonso. Ella tomó estas fotos en fecha muy próxima a la ejecución de las pinturas, por encargo de los propios artistas. En muchos casos realiza sólo un registro de la obra, como en el caso de la obra de caballete de Diego Rivera o en ciertos tableros, como el de Sangre de los mártires agrarios, de Chapingo, o La orgía, de la Secretaría de Educación Pública; pero en otros establece una recreación fotográfica de los murales, una interrelación con ellos por sus encuadres, conduciéndolos así a una apreciación específica de ciertos detalles, ritmos, juegos formales, asociaciones; es el 
DOI: http://dx.doi.org/10.22201/iie.18703062e.2001.78.2010

180 MARICELA GONZÁLEZ CRUZ MANJARREZ

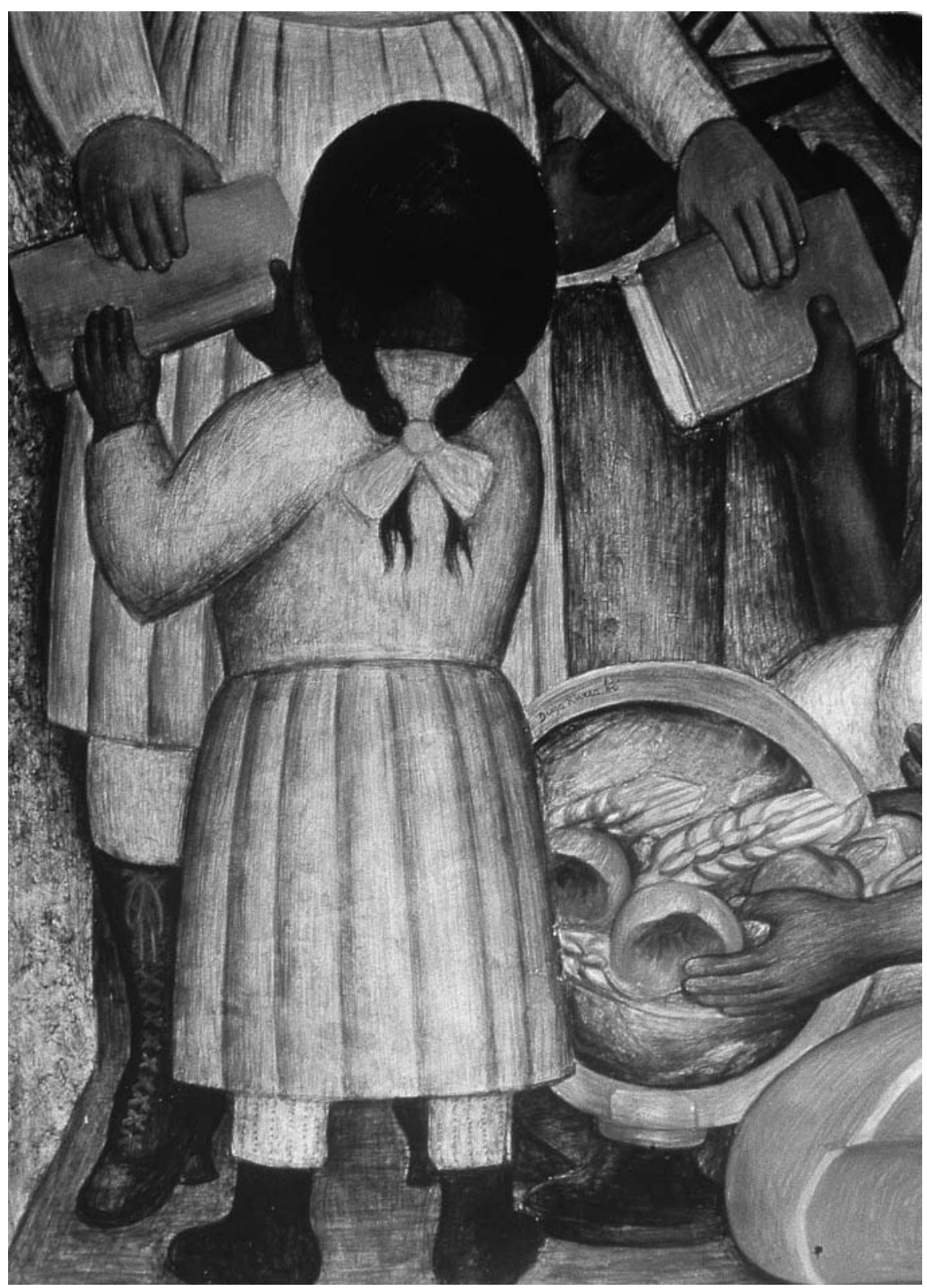

Figura 4. D iego Rivera, Alfabetización, detalle, tablero del Corrido de la Revolución, Secretaría de Educación Pública. Colección T ina M odotti, Archivo Fotográfico iie-unam. 


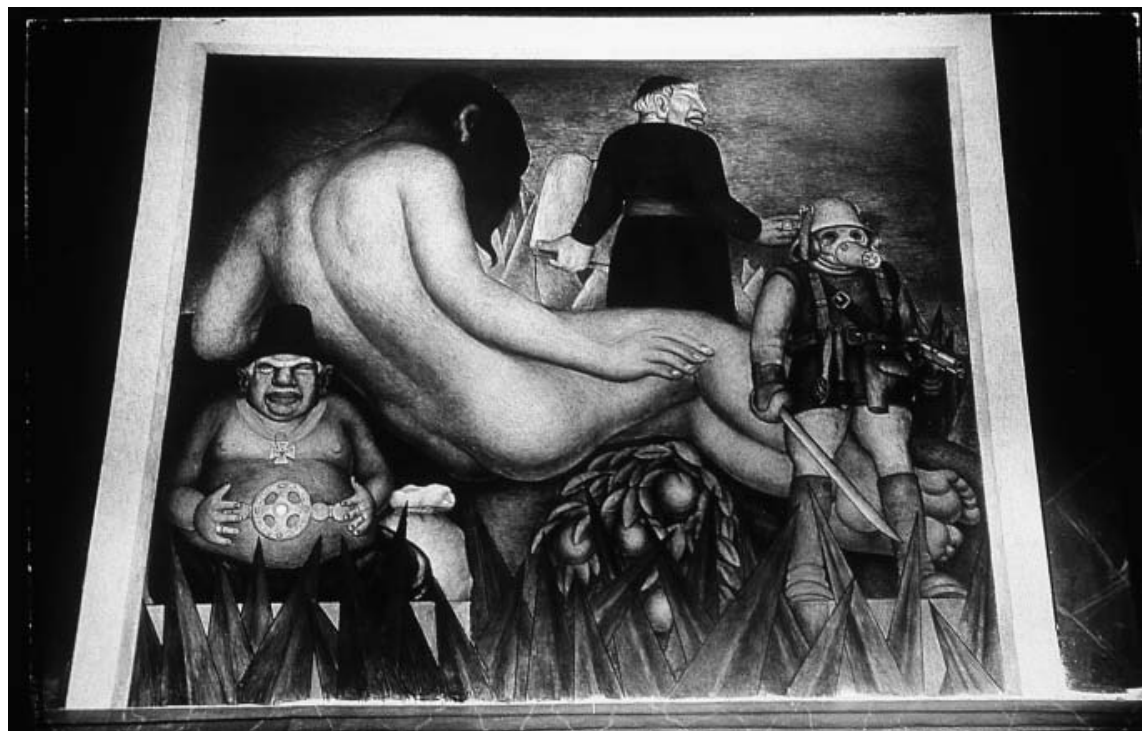

Figura 5. D iego Rivera, T ierra oprimida, muro lateral poniente, D esarrollo social, Salón de Actos, Universidad Autónoma Chapingo. Colección Tina M odotti, Archivo Fotográfico iie-unam.

caso del tablero de la sep, Queremos trabajar, donde destaca al personaje de la parte superior con la vírgula de la palabra y el texto: "toda la riqueza del mundo proviene del campo", o el de Alfabetización, donde se establece un paral elismo entre los productos de la tierra y la cultura, con la niña que recibe un libro y a su derecha aparecen espigas en un cesto en cuyo borde vemos la firma de D iego Rivera con la hoz y el martillo, o en el ritmo en dos tomas distintas del tablero La danza de los listones (figura 4 ).

Curiosamente, ella misma fotografió tableros murales en los que D iego la pintó resaltando su actividad como luchadora social o representando su beIleza física. Aparece desnuda en el mural de La tierra dormida, ubicado en el arco de soporte del coro, y en el tablero La tierra oprimida, dentro de la serie de los murales del D esarrollo Social, ambos en el Salón de Actos (ex capilla) de Chapingo. Sugiere su carácter revolucionario en la Secretaría de Educación Pública, donde la representa sosteniendo una canana junto con su compañero Julio Antonio M ella, el destacado revolucionario cubano; ambos están ubicados en el lado derecho del famoso tablero conocido como Entrega de armas o En el arsenal, el cual significativamente da comienzo a la serie de tableros del Corrido de la Revolución (figura s). 


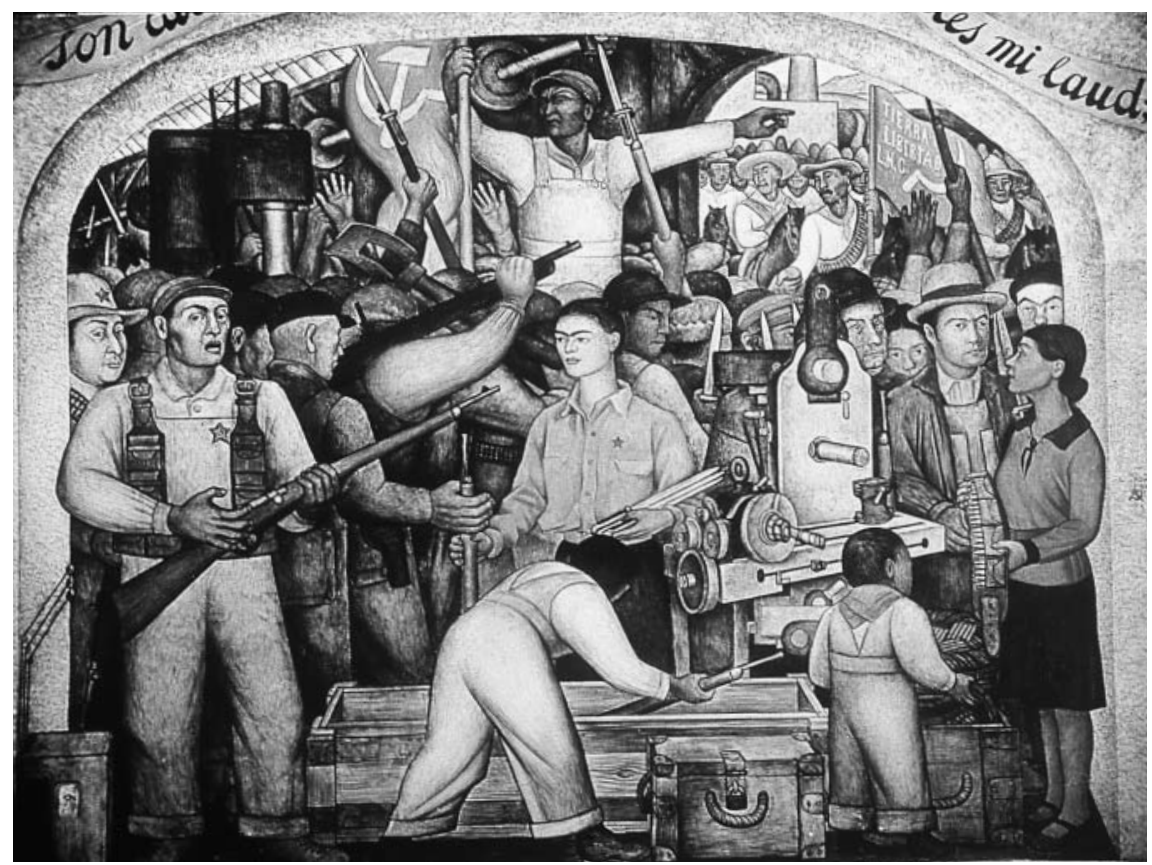

Figura 6. D iego Rivera, Entrega de armas o En el arsenal, Corrido de la Revolución, Secretaría de Educación Pública. Colección Tina M odotti, Archivo Fotográfico iie-unam.

D iego Rivera incluye en este mural, como personaje central, a Frida KahIo. Junto a M ella y Tina M odotti aparece Vittorio Vidali, y entre obreros y trabajadores, en el extremo izquierdo, portando un sombrero con una pequeña estrella, coloca a D avid Alfaro Siqueiros (figura 6).

En la serie de fotografías de la colección de Tina M odotti del Instituto de Investigaciones Estéticas podemos advertir su ojo fotográfico a través del énfasis en ciertos detalles, como es el caso de los rostros, ya sea de personajes conocidos como Emiliano Zapata o Frida Kahlo, de figuras simbólicas como obreros y campesinos (tableros como Un solo frente y Q ueremos trabajar), de mujeres (U nión, Alfabetización y Garantías) o de grupos populares (Reparto de tierras).

Un detalle reiterativo en sus imágenes es el de las manos. Al reencuadrar la fotógrafa las manos que pinta Rivera en sus murales, destaca su significación ideológica, como en la parte superior de algunos tableros y en techos y 


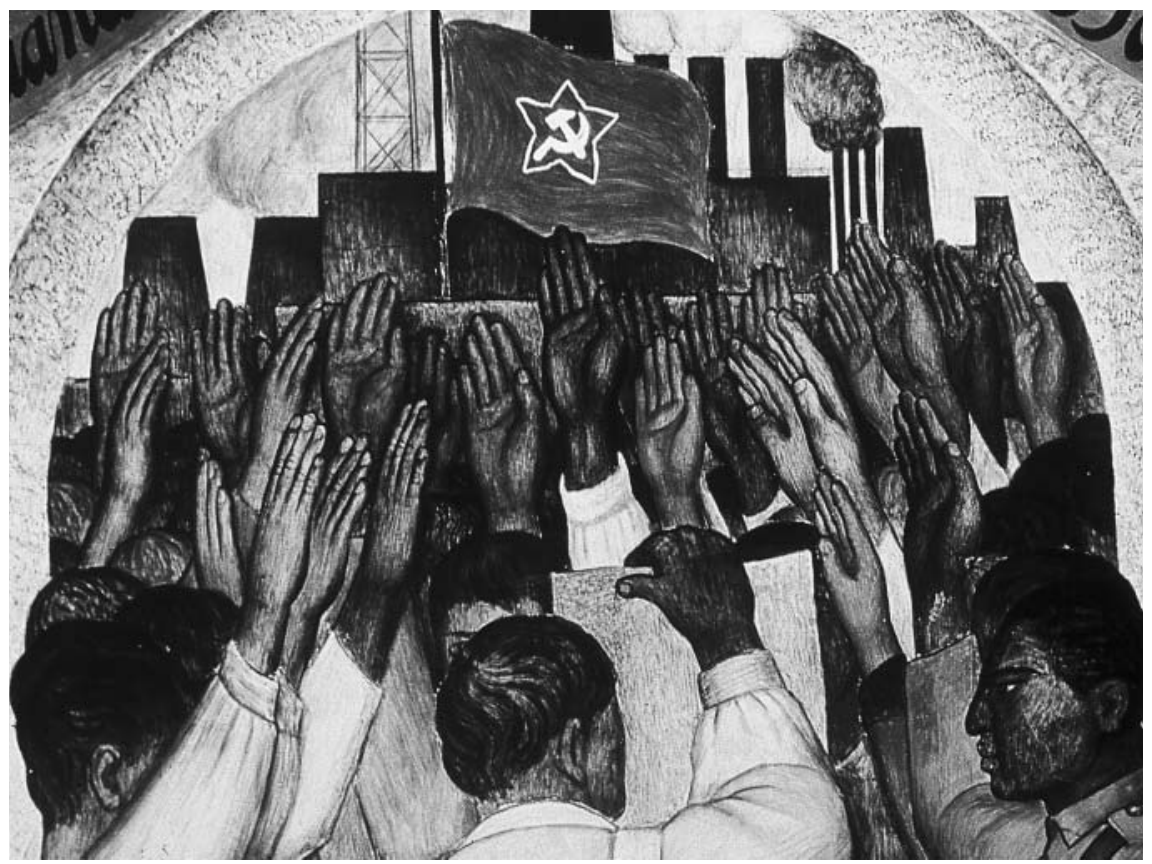

Figura 7. Diego Rivera, La protesta, detalle, Corrido de la Revolución, Secretaría de Educación Pública. Colección Tina M odotti, Archivo Fotográfico iie-unam.

bóvedas de Chapingo; pero también resalta el tratamiento artístico y formal. Así, observamos las virtuales líneas rectas ascendentes establecidas por las manos de La protesta, o del tablero El que quiera comer, que trabaje. Vemos también la composición a partir de líneas curvas en la cual las manos y los cuerpos adquieren suaves formas redondeadas, como en Las eras y en La danza de los listones. Están también las manos firmes que señalan, en Reparto de tierras o La cooperativa (figura 7 ).

El motivo de las manos y de los puños se encuentra constantemente en murales y cuadros realizados particularmente de los años veinte a los cuarenta, y en algunos de Siqueiros de los años cincuenta. Algunas fotos de Tina M odotti se titulan $M$ anos de lavandera, $M$ anos de titiritero, y, siguiendo prácticas vanguardistas, como las del propio Weston, en sus imágenes fragmenta el cuerpo y se centra en el motivo de interés. En la década de los treinta, fotógrafos como Aurora Eugenia Latapí, Luis M árquez o M anuel Álvarez Bra- 




Figura 8. Tina M odotti, $M$ anos de titiritero. Foto tomada de $M$ argaret H ooks, Tina M odotti, Photographer and Revolutionary, Londres, Pandora, 1993, p. 190.

vo, entre otros, también tienen fotos donde las manos son el motivo principal (figuras 8, 9 у го).

Finalmente, hay que destacar la cantidad de fotos que reproducen fragmentos de los tableros murales en los que aparecen niños y mujeres, en diferentes actitudes y actividades. Éste es un enfoque muy personal de Tina M odotti; basta recordar sus fotos de madres con sus hijos, de niños y mujeres. En sus fotografías rescata escenas como la del niño sentado junto a un perro, comiendo un taco (La lluvia); niños que se encuentran en las rítmicas composiciones de La danza de los listones o Los frutos de la Revolución; niños que escriben (Fin del corrido); la del niño que con ternura toma la mano de un adulto (EI herido) o la imagen de la propia hija de Rivera (Lupe niña), retratada en el tablero U nión.

En M éxico, además de esta colección de fotos del iie, se encuentran fotos de Tina M odotti en la Fototeca del inah, de Pachuca, en el M useo de Arte M oderno, la C asa L amm ${ }^{6}$ y en colecciones particulares (como la de Ava Vargas). En el extranjero se resguarda material fotográfico de Tina en el Patrona- 
DOI: http://dx.doi.org/10.22201/iie.18703062e.2001.78.2010

TINA MODOTTI Y EL MURALISMO

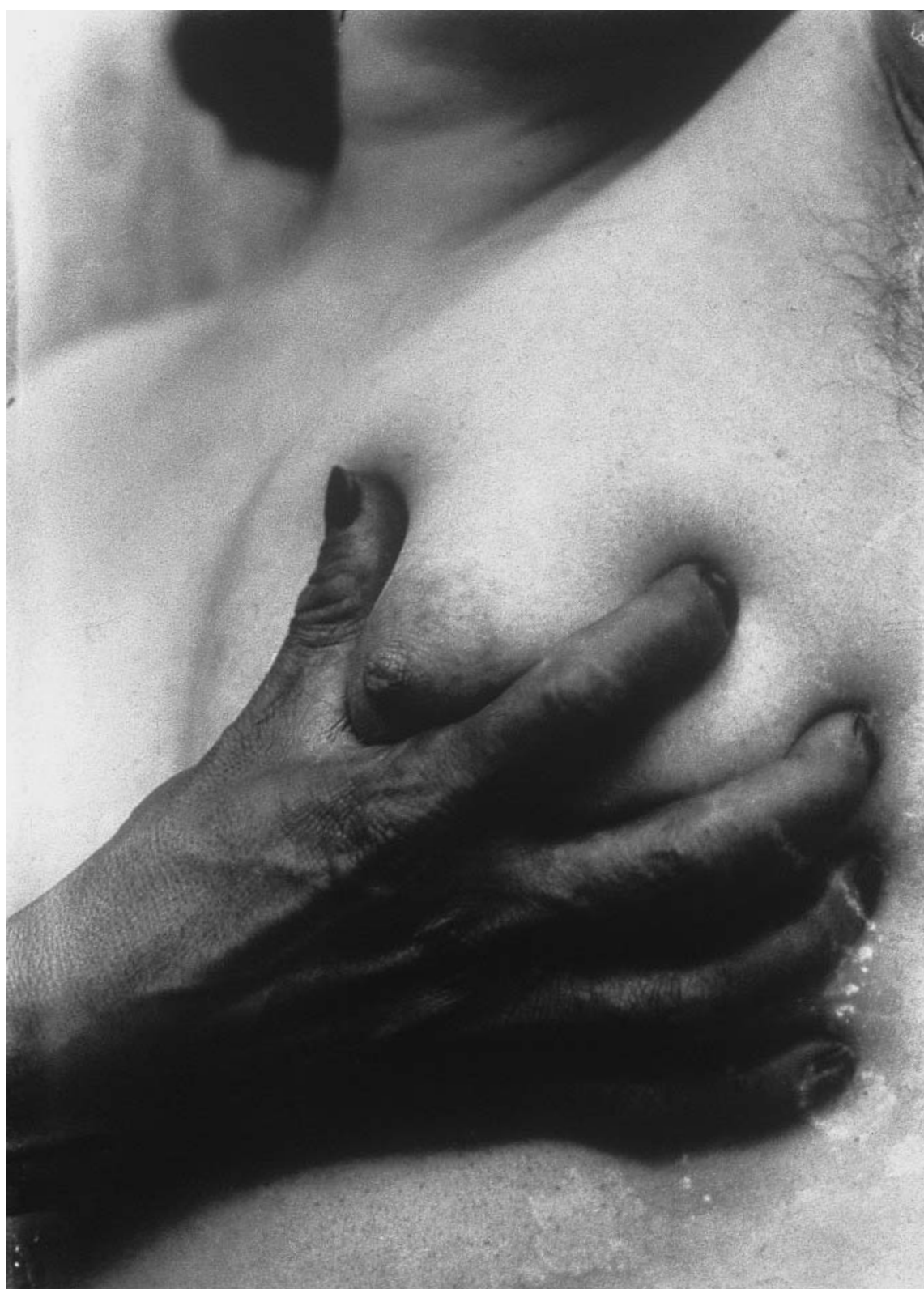

Figura 9. Luis Márquez, Sin título, década de los treinta. Colección Luis M árquez, Archivo Fotográfico iie-unam. 
DOI: http://dx.doi.org/10.22201/iie.18703062e.2001.78.2010

186 MARICELA GONZÁLEZ CRUZ MANJARREZ

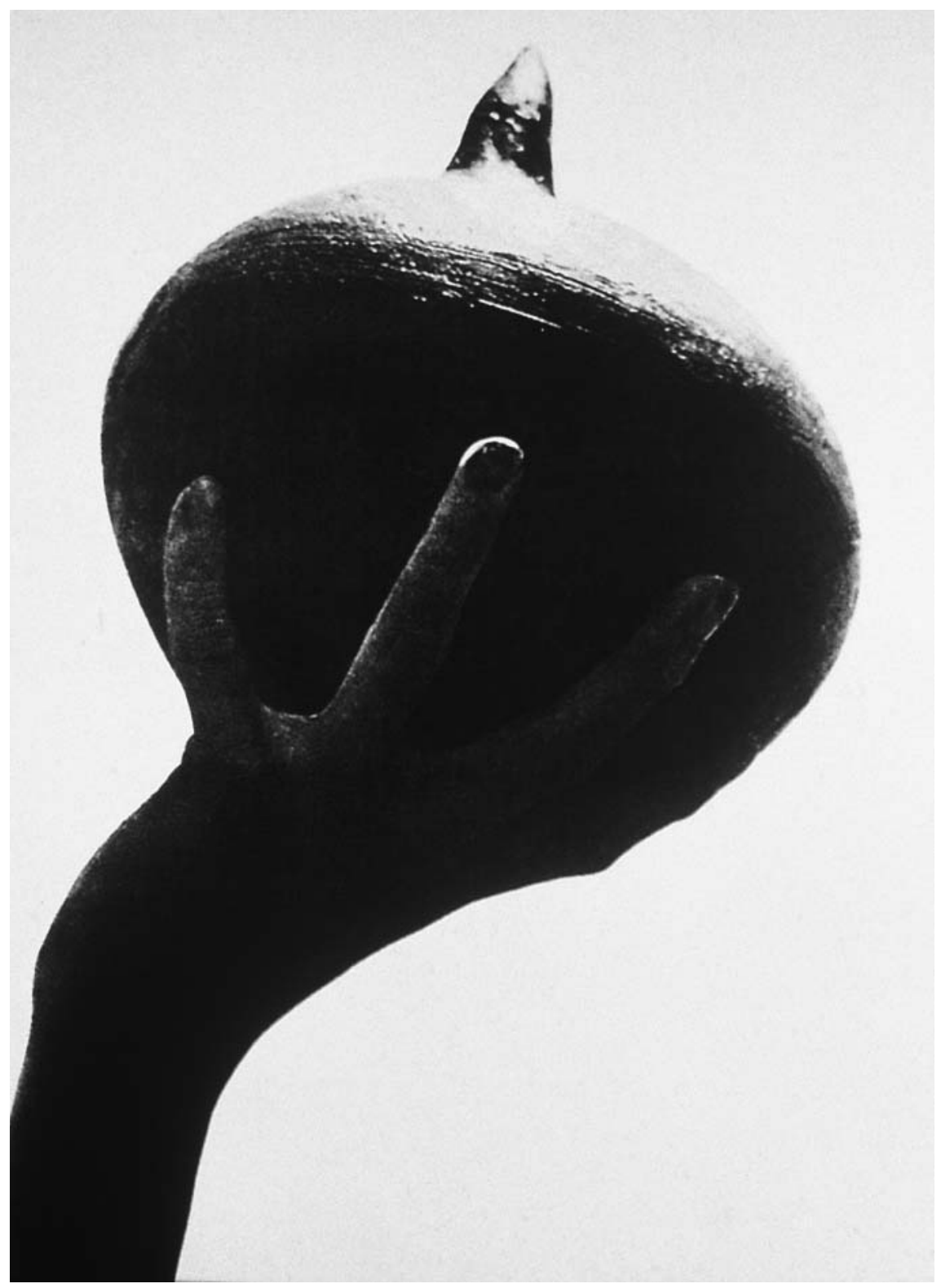

Figura io. Edward W eston, M ano de Amado Galván, 1926. Foto tomada de Gilles M ora et al., Edward W eston. Forms of Passion, Boston-Londres, H arry N. Abrams, 1995, p. 92. 
to Tina M odotti en U dine, Italia, y en Estados Unidos se encuentran fotografías en Rochester, N ueva York, en la George Eastman H ouse y en California, en la Weston Gallerie, entre otros lugares.

Cada vez hay más investigaciones, exposiciones y publicaciones sobre esta fotógrafa y su obra; es el caso de la reedición de uno de los primeros estudios, que data de i975: el de M ildred Constantine; 7 de la compilación de las cartas de M odotti y Weston, realizada por Antonio Saborit en I991; ${ }^{8}$ del video documental de Alejandra Islas (guión) y Raquel Bolaños (investigación), de I995-1996; del cortometraje de M aría Bardischewski y U rsula Jeshel, de la República Federal Alemana de $198 \mathrm{r} ; 9$ la investigación de M argaret $\mathrm{H}$ ooks Tina M odotti, Photographer and Revolutionary, ${ }^{\text {Io }} 0$ la mencionada tesis de $\mathrm{M}$ ariana Figarella, de la cual adoptamos varias ideas para este artículo y que será publicada por el Instituto de Investigaciones Estéticas.

Entre las exposiciones, cabe destacar la de enero de $1996,{ }^{\text {II }}$ presentada en el C entro de la Imagen, titulada Tina M odotti, I929, una nueva mirada, en la cual se mostraron documentos y 4i de las 60 fotografías que se presentaron en la significativa exposición de M odotti en la Biblioteca $\mathrm{N}$ acional de la Universidad, en 1929.

Además de múltiples artículos, otras publicaciones son las de Christiane Barkhausen Canale, de 1989; ;2 Pino Cacucci, de 1993; ${ }^{13}$ Elena Poniatowska, de $1992,{ }^{\text {I4 }}$ y G arcía Pena y Saborit, de $1999 .{ }^{\text {I5 }}$

Como podemos advertir, la obra y las actividades de esta fotógrafa italiana son todavía objeto de estudio y su figura sigue atrayendo a especialistas de distintas áreas; por ello, trabajos que en su momento resultaban aislados, como el del artículo mencionado del maestro Xavier M oyssén, son ahora significativos. \&

7. Tina M odotti, una vida frágil, M éxico, Fondo de Cultura E conómica, 1979.

8. U na mujer sin país, M éxico, Cal y Arena, I99ı.

9. Filmoteca de la unam.

Io. Londres, H arper Collins-Pandora, I993, quien cedió los derechos de su libro a una productora cinematográfica.

II. Este año se celebró el primer centenario del nacimiento de Tina, junto con el de Siqueiros y Xavier Guerrero.

I2. Verdad y leyenda deT ina M odotti, Cuba, Casa de las Américas, I989.

I3. Los fuegos, las sombras, el silencio. U na biografía de Assunta Lugia AdelaideT ina M odotti, M éxico, Joaquín M ortiz, 1993.

I4. Tinísima, M éxico, Era, 1992.

I5. Tina M odotti, vivir y morir en M éxico, M éxico, Conaculta, I999. 
DOI: http://dx.doi.org/10.22201/iie.18703062e.2001.78.2010

188

MARICELA GONZÁLEZ CRUZ MANJARREZ

Bibliografía

Alfaro Siqueiros, D avid, "U na trascendental labor fotográfica”, en El Informador. Diario Inde pendiente, Guadalajara, Jalisco, viernes 4 de septiembre de 1925.

Brenner, Anita, Ídolos tras los altares, M éxico, D omés, 1983 (con fotos de Tina M odotti y Edward W eston).

Carleton, Beals, "T ina M odotti", en el catálogo Frida Kahlo y T ina M odotti, M éxico, M useo $\mathrm{N}$ acional de Arte, in ba, 1983 (apareció en CreativeArts, N ueva York, febrero de 1923).

Constantine, M ildred, Tina M odotti, una vida frágil, M éxico, Fondo de Cultura Económica, 1979.

Figarella M ota, M ariana, Edward W eston y T ina M odotti en M éxico. Su inserción dentro de las estrategias estéticas de arte posrevolucionario, M éxico, unam, Instituto de Investigaciones Estéticas, en prensa.

González Cruz M anjarrez, M aricela, Tina M odotti y el muralismo mexicano, M éxico, un amiie, 1999, Colecciones del Archivo Fotográfico, I.

H ooks, M argaret, Tina M odotti, Photographer and Revolutionary, Londres, Harper CollinsPandora, 1993.

M odotti, Tina, "Sobre la fotografía", en M exican Folkways, vol. 5, núm. 4, octubrediciembre de 1929 .

M oyssén, Xavier, "U na colección de fotografías de Tina M odotti y José M aría Lupercio", en Anales del Instituto de Investigaciones Estéticas, vol. XII, núm 44, M éxico, un am-iie, 1975.

0 rozco, J osé Clemente, El artista en N ueva York. Cartas a J ean Charlot. T extos inéditos: I925I929, M éxico, Siglo XXI, I979.

Rivera, D iego, "Edward W eston y Tina M odotti", en M exican Folkways, núm. 6, abril-mayo de 1926.

Saborit, Antonio, U na mujer sin país, Las cartas de T ina M odotti a Edward Weston, I92I-I93I, M éxico, Cal y Arena, I99I. 